\title{
Cuidados, género y transformación de identidades
}

\author{
Concepción FERNÁNDEZ VILLANUEVA \\ Universidad Complutense de Madrid \\ Departamento de Psicología Social \\ cfvillanueva@cps.ucm.es \\ Alba ARTIAGA LEIRAS \\ Universidad Complutense de Madrid \\ Departamento de Psicología Social \\ alarleiras@hotmail.com \\ Ma Celeste DÁVILA DE LEÓN \\ Universidad Complutense de Madrid \\ Departamento de Psicología Social \\ mcdavila@cps.ucm.es
}

Recibido: 10-05-2012

Aceptado: 15-10-2012

\begin{abstract}
RESUMEN
Ante la actual crisis de los cuidados, han surgido diversas medidas institucionales que pretenden revisar el desigual reparto de responsabilidades de los cuidados entre el mercado, el estado, la familia y la sociedad civil, como es, en el caso español, la puesta en marcha de la Ley de Promoción de la Autonomía Personal y Atención a personas en situación de dependencia. En este artículo analizamos los marcos de sentido que promueve esta ley, así como el contexto actual de transformación en la organización social de los cuidados que favorece esta iniciativa, para comprender su contribución a la reformulación de las identidades de las personas cuidadoras y del orden social de género. Asimismo, entendiendo las políticas públicas como resultado de luchas simbólicas entre distintos actores sociales, en este artículo se apuntarán las principales interacciones y discursos hegemónicos que inciden en la definición de la realidad social en torno a la valorización de los cuidados y a su reparto.
\end{abstract}

Palabras clave: cuidados, políticas públicas, transformación social y género

\section{Social care, gender and the transformation of identities}

\begin{abstract}
Nowadays social care crisis facilitates the emergence of different institutional measures that try to reformulate the unequal distribution of care responsibilities between the market, the state, the family and the civil society, as it is, in the Spanish case, the development of the Law of the Promotion of Personal Autonomy and the Attention to dependent people. In this article, we analyze the frames of sense promoted by this law, as well as the current context in which the social organization of care is being transformed, to understand their contribution to a reformulation of the identities of the care givers and the gender's social order. Also, the understanding of public policies as a result of the symbolic fights between different social actors, allows
\end{abstract}


us to analyze the main interactions and the hegemonic discourses that influence the definition of social reality, related to social care recognition and its distribution.

Keywords: social care, public policies, social transformation and gender

\section{REFERENCIA NORMALIZADA}

Fernández Villanueva, C., Artiaga Leiras, A., Dávila de León, Ma C. (2013). Cuidados, género y transformaciones de identidades. Cuadernos de Relaciones Laborales Vol. 31, núm. 1, p. 57-89.

SUMARIO: Introducción. 1. La LAAD: ¿retórica o redistribución de los roles de género en los cuidados?. 2. Los cuidados como carga o responsabilidad a pesar de la laad: una tarea para mujeres, migrantes y/o precarias. 3. Perspectivas de futuro en la redistribución de los cuidados y el género: obstáculos estructurales y psicosociales. 4. Conclusiones. 5. Bibliografía.

\section{Introducción}

El trabajo de cuidar se define y se diferencia de los otros por un rasgo fundamental: es trabajo relacional, una tarea para los demás. "Se realiza en un cara a cara entre personas situadas en una relación de dependencia ya que una es tributaria de la otra para su cuidado y su bienestar" (Letablier, 2007, p.66). Tanto las prácticas ("lo que hay que hacer"), como las relaciones que establece (para quien o quienes se hace), las negociaciones que implica su desarrollo (delegación, peticiones, demandas, reparto y resolución de las rutinas cotidianas) y el sentido que fundamenta o se atribuye al concepto de cuidado (satisfacción, deber, obligación o responsabilidad, por ejemplo) se desarrollan en el terreno de las relaciones interpersonales.

Aunque el trabajo de cuidados abarca varias dimensiones, algunas similares a las de otros trabajos, como la responsabilidad material (el trabajo o tarea concreta a realizar) y la dimensión económica (el coste), se caracteriza por otras dimensiones más peculiares y definitorias como las dimensiones psicológicas y morales. La emoción, la afectividad o los sentimientos están fuerte e inevitablemente ligados a la tarea. La afectividad se hace necesaria, y se deriva y depende de la relación interpersonal entre la persona que cuida y la persona que recibe estos cuidados. La dependencia afectiva y la variabilidad de necesidades del destinatario de los cuidados implica que las tareas que incluye el trabajo de cuidados son en general difusas e imprecisas, y siempre deben concretarse en la relación interpersonal en la que se llevan a cabo.

El trabajo emocional es una parte integrante de muchas tareas laborales, especialmente en el sector de los servicios. No existe una definición clara sobre el trabajo emocional, algunos autores lo han definido como la acción de expresar la emoción apropiada (Ashforth y Humphrey, 1993) o el esfuerzo, la planificación y control necesarios para expresar las emociones deseables durante las transacciones interpersonales (Morris y Feldman, 1996). Las actividades integradas en el llamado "amor labour" se empiezan a incluir como trabajo a pesar de las resistencias de los economistas formales (Lynch, 2007). Incluso se ha intentado establecer, supervisar y medir su rendimiento (Taylor, 1998), pero es en el ámbito de los cuidados donde se ejemplifica de forma más clara el "amor labour". Tanto sus prácticas como las relaciones que 
establece y las negociaciones que supone no podrían realizarse sin una implicación emocional positiva aunque sea mínima entre el trabajador/a y el destinatario/a del trabajo. Se realice o no dentro del ámbito doméstico, es precisamente en esa implicación emocional así como en el coste o satisfacción psicológica que implica, donde reside la diferencia con el propiamente llamado trabajo doméstico.

La relación interpersonal estrecha en la que trascurren los cuidados implica una fuerte dimensión moral, que se basa en deberes u obligaciones. Según la evolución de las sociedades en relación a los nuevos modos de organización social, las obligaciones y los deberes del cuidado se depositan sobre todo en la familia, y además en el mercado, el estado o el voluntariado, pero en función de cada sociedad este reparto incide más en unos u otros actores proveedores de cuidados

El trabajo de cuidados ha sido tradicionalmente asignado y secularmente definido como trabajo de mujeres. El "deber ser" del concepto de cuidado (care en inglés) alude a la atención personal propia de la función maternal, la nurturance, es decir, el amor materno, que se extiende por generalización al amor a las personas y a la predisposición para la atención y el cuidado, se concibe como una disposición natural de las mujeres. Como otras tareas propias del rol tradicional femenino, el trabajo de cuidados se ha situado en el ámbito doméstico y en el ámbito de la responsabilidad moral, pero no dentro de la categoría de empleo remunerado, y frecuentemente, ni siquiera en la categoría de "trabajo".

Las interpretaciones feministas cuestionan las relaciones entre el trabajo remunerado y no remunerado, y las fronteras entre la esfera pública y privada, lo productivo y lo improductivo. Paralelamente, comienzan a influir en el reconocimiento y valoración de los cuidados, plantean su reformulación y categorización, y exigen la implicación de todos los actores sociales en esta responsabilidad. En este sentido, la noción de "trabajo invisible" sirve de base y apoyo a las exigencias de reconocimiento, de valoración social y de remuneración ${ }^{1}$.

Los países europeos experimentan una crisis de los cuidados debido a varios factores, entre ellos, el envejecimiento de la población, los cambios en los modelos de familia, la mayor participación de las mujeres en el mercado de trabajo formal, así como el declive de los instrumentos colectivos de protección social. De este modo, según la relación de fuerzas de los distintos actores sociales (movimientos feministas, de mayores, de personas con diversidad funcional, patronal y sindicatos), las actitudes previas de cada país hacia los cuidados y la protección social, y las representaciones colectivas acerca de la responsabilidad social ante los cuidados, se producen transformaciones hacia la redistribución de responsabilidades en las funciones del cuidado y se desarrollan algunas medidas de intervención frente al

${ }^{1}$ Un ejemplo de esta demanda de valoración es la siguiente conclusión de $\mathrm{M}^{\mathrm{a}}$ Angeles Duran: "Si se valorasen y cuantificasen las horas prestadas por los cuidadores a precios de mercado el sector informal podría acercarse a una parte considerable de lo que representa el gasto sanitario" (Durán, 1999). 
reparto de los cuidados, como es, en el caso español, La Ley de Promoción de Autonomía Personal y de Atención a Personas en Situación de Dependencia (LAAD).

El objetivo de este artículo es presentar cómo se relacionan en el contexto español las normas políticas que pretenden paliar la llamada crisis de los cuidados en concreto, la LAAD, con la redistribución por genero de las tareas implicadas en el cuidado de las personas y las posibilidades de revalorización de dichas tareas en el futuro próximo. En línea con este objetivo, consideramos necesario conocer las luchas simbólicas que plantean los distintos actores sociales en la elaboración de los cambios legislativos pertinentes, en este caso, la LAAD, para entender las verdaderas posibilidades de redistribución social de las necesidades del cuidado y la transformación de los roles e identidades de genero que se derivan de dicha normativa legal.

Para la elaboración del artículo nos basamos en el análisis del trabajo de campo, realizado en el marco de dos proyectos de investigación ${ }^{2}$, que consiste en veinte entrevistas en profundidad a los distintos actores clave (IMSERSO, sindicatos, patronal, organizaciones de mujeres, de mayores, de personas con diversidad funcional, etc.) sobre la elaboración de la LAAD y la cuestión de los cuidados.

En primer lugar analizaremos la retórica en torno a los cuidados en el marco de la LAAD para comprender si afecta a la distribución de los roles de género, qué aspectos se problematizan, los conceptos que se difunden y si se promueve un marco normativo en torno a la redistribución social de los cuidados. De este modo, para ello analizaremos el discurso de la LAAD y diversos documentos publicados en relación con ésta ${ }^{3}$.

2 "Producción política de la categoría de cuidados: prácticas institucionales y experiencias de implementación en el atención a la dependencia "(Proyecto FEM-201018827, MICINN).

"Políticas públicas y producción política de la categoría de cuidados: el caso de la Ley de dependencia" (Entidad financiadora: Instituto de la Mujer).

${ }^{3}$ IMSERSO (2004) Libro Blanco de Atención a las personas en situación de dependencia en España. Ministerio de Trabajo y Asuntos Sociales. Madrid.

- Gobierno, patronal y sindicatos (2004) Acuerdo sobre Competitividad, Empleo Estable y Cohesión Social.

- Gobierno, patronal y sindicatos (2005) Acuerdo sobre la acción protectora de la atención a las situaciones de dependencia.

- Anteproyecto de Ley de Promoción de la Autonomía Personal y Atención a las personas en situación de dependencia (2006).

- Ministerio de Trabajo y Asuntos Sociales (2006) Memoria del análisis de impacto normativo, económico, de género e igualdad de oportunidades, no discriminación y accesibilidad universal. MTAS. Madrid.

- Consejo Económico y Social (2006) Dictamen 3/2006 sobre el Anteproyecto de Ley de Promoción de la Autonomía Personal y Atención a las personas en situación de dependencia. 
En segundo lugar, presentaremos algunos datos estadísticos y cualitativos en relación con la situación actual de reparto de los cuidados ante un contexto de cambio legislativo y crisis de los cuidados, para entender las tendencias y transformaciones en torno a las identidades de los cuidados, las cargas y el reparto de las responsabilidades.

$\mathrm{Y}$ en tercer lugar, señalaremos algunas reflexiones relativas a las posibilidades que nos ofrecen las actuales luchas simbólicas de los distintos actores sociales y las tendencias actuales de las identificaciones de género, para entender hacia dónde apuntan los nuevos marcos de intervención y de pensamiento en torno a la organización social de los cuidados.

\section{La LAAD: ¿retórica o redistribución de los roles de género en los cuidados?}

En nuestro país, un eslabón fundamental que, a priori, plantea la redistribución de responsabilidades y tareas del cuidado es la Ley 39/2006, de 14 de diciembre, de Promoción de la Autonomía Personal y Atención a las personas en situación de dependencia (LAAD). Como instrumento modernizador de los derechos de las personas, de los derechos de ciudadanía y de la protección, dicha ley suscitó la expectativa de generar una redistribución de las responsabilidades en torno a los cuidados y el reconocimiento y valorización del trabajo que han realizado tradicionalmente muchas mujeres.

Ante todo, se hizo hincapié en el elevado número de empleos que se crearían, lo que daría la posibilidad de que muchas mujeres se insertasen en este mercado laboral, con lo cual encontrarían un justo reconocimiento social quienes ya se estaban dedicando a la realización de esta actividad sin ningún tipo de remuneración o reconocimiento. La transformación del status social de la tarea y su valorización en el mercado se plantea como una sustancial restructuración y un avance importante hacia el replanteamiento de los roles de género.

No obstante, el análisis más detallado de la LAAD y de la regulación que la acompaña muestra que la redistribución de las responsabilidades y de los derechos en función del género resulta más bien retórica. Aunque se refiere insistentemente a la consecución de derechos y a la igualdad de oportunidades, el termino igualdad de oportunidades -que se cita 10 veces-, alude a un tipo de sujeto considerado dependiente (personas mayores o personas con diversidad funcional), nunca hay una referencia a la desigualdad de género. La redistribución de las oportunidades de

- Consejo de Estado (2006) Dictamen sobre el Anteproyecto de Ley de Promoción de la Autonomía Personal y Atención a las personas en situación de dependencia.

- Ley de 39/2006 de Promoción de la Autonomía Personal y Atención a las personas en situación de dependencia. 
género queda fuera de lo que se considera "el problema", tal y como se refleja en la LAAD.

"El Sistema de Atención de la Dependencia es uno de los instrumentos fundamentales para mejorar la situación de los servicios sociales en nuestro país, respondiendo a la necesidad de la atención a las situaciones de dependencia y a la promoción de la autonomía personal, la calidad de vida y la igualdad de oportunidades" (LAAD BOE núm. 299 Viernes 15 diciembre 2006 pp.44143 incluir referencia de la ley).

La promoción de la autonomía personal y la calidad de vida parecen anteceder incluso sustituir como objetivos a la igualdad, al menos en teoría, ya que a juzgar por las quejas de los colectivos de gente con discapacidad tampoco estos se cubren satisfactoriamente.

Sumado a ello, en todos los casos, el criterio de igualdad de oportunidades se refiere siempre a la valoración de las necesidades de las personas, usuarias o necesitadas de protección, no a los/as trabajadores/as que les prestan los servicios.

El objetivo de igualdad de oportunidades resulta difícil de concretar, incluso de entender, tal como está formulado. Si se refiere a la igualdad de derechos y oportunidades entre las personas "autónomas" y las personas con necesidades de dependencia, (con un criterio tan dicotómico, diferenciador y médico) puede convertirse en un objetivo inalcanzable, ya que no serian colectivos comparables. Así pues, este principio resulta en cierto modo retórico, vacío de contenido por la inconcreción en su contenido y la falta de referencias sobre a quien se aplica, con la excepción de los usuarios. Por el contrario si queda mas delimitado el objetivo de protección. La ley se justifica y define como "una nueva modalidad de protección social que amplía y complementa la acción protectora del Estado y del Sistema de la Seguridad Social". El termino protección no sólo es el más citado (aparece 30 veces en el texto de la ley) sino el mas matizado, y el que tiene más condicionantes y referentes (protección sanitaria, protección social, protección a los ciudadanos o protección a las personas en situación de dependencia, por ejemplo). Términos como intensidad de la protección o niveles de protección enfatizan aún más la importancia de este concepto.

El Proyecto de ley parte del reconocimiento de un principio importante y positivo: el derecho individual y subjetivo de todas las personas, sin discriminación de ningún tipo, y por tanto, sin discriminación de género, en situación de dependencia, a recibir atención. "La universalidad en el acceso de todas las personas en situación de dependencia, en condiciones de igualdad efectiva y no discriminación, en los términos establecidos en esta Ley" (art. 3 principios de la ley).

$\mathrm{La}$ "inclusión de la perspectiva de género, teniendo en cuenta las distintas necesidades de mujeres y hombres" (art. 3 LAAD) ya que promete y explicita la protección de las mujeres posibles usuarias, que son una población dependiente mayoritaria y potencialmente más desprotegida. Según los últimos datos del Sistema para la Autonomía y Atención a la Dependencia, actualizados a 1 de Mayo (SAAD- 
IMSERSO, 2012) las personas solicitantes y beneficiarias de las prestaciones de dependencia son mayoritariamente mujeres (el $65,46 \%$ y el $66,5 \%$, respectivamente). Cuando se atiende a la edad, se encuentra que las diferencias con los varones se hacen aún más notables a partir de los 80 años, el 76,7\% de los beneficiarios son mujeres y el $23.3 \%$ varones.

Muchas mujeres pueden quedar en situación de vulnerabilidad extrema, ya que su esperanza de vida es mayor y de hecho, se constata un mayor número de dependientes mujeres con niveles más severos de incapacidad en las edades más avanzadas y con menores niveles de ingresos (Castejón, Esparza y Abellán, 2007). Por otra parte, este colectivo suele ser más vulnerable económicamente, ya que en su inmensa mayoría se trata de viudas o de mujeres que no han trabajado nunca en trabajos remunerados. Las redes sociales de las más mayores se han ido debilitando y deteriorando, volviéndose menos tupidas y diversas (Puga, 2007), muy probablemente por la pérdida de contactos sociales al fallecer familiares y amigos, y por experimentar una capacidad funcional limitada que impide o dificulta su participación social en muchos ámbitos, lo que aumenta su fragilidad, su necesidad de protección y de cuidado.

Así pues, la perspectiva de género aparece explícita aunque tímidamente, y en este caso se enfatiza la cuestión de las distintas necesidades de las personas beneficiarias de la ley y su aplicación por sexo.

No obstante, la ley supone un cierto avance en el reconocimiento de cuestiones sustanciales que podrían redundar en la trasformación de las identidades de género, y al mismo tiempo favorece el mantenimiento de ciertos privilegios y prioridades sociales. Esta medida legislativa plantea un reconocimiento simbólico de ciertas cuestiones, de modo que los cuidados pasan de la esfera de las obligaciones morales de las mujeres a la esfera de la responsabilidad social,

"Además establece, que un trabajo que formaba parte de las obligaciones morales que tenian que realizar las mujeres, promueve esa idea de que ya las mujeres no tienen esa obligación social de tener que cuidar a todo el mundo" (Representante del Instituto de la Mujer)

En la Ley, se reconoce una crisis en el modelo tradicional de reparto de roles en el hogar y la necesidad de atender a situaciones que han sido resueltas casi en exclusividad por las mujeres ${ }^{4}$. Pero el modo de resolverlo a través de la mercantili-

4 "Es un hecho indudable que las entidades del tercer sector de acción social vienen participando desde hace años en la atención a las personas en situación de dependencia y apoyando el esfuerzo de las familias y de las corporaciones locales en este ámbito. Estas entidades constituyen una importante malla social que previene los riesgos de exclusión de las personas afectadas. La necesidad de garantizar a los ciudadanos, y a las propias Comunidades Autónomas, un marco estable de recursos y servicios para la atención a la dependen- 
zación y la centralidad de la prestación económica, promueve el mantenimiento de la división sexual del trabajo. De algún modo, se reconoce el valor económico y social de las tareas de las cuidadoras, a través de la prestación económica para cuidados en el entorno familiar; pero sin embargo, esta misma medida refuerza la distribución de roles en torno a los cuidados y favorece la llamada por algunas autoras "altruismo obligatorio" (Lewis y Daly, 2011) de las mujeres en el hogar en unas condiciones que no son equiparables a otros trabajos.

Además, deja de lado otro de los supuestos en relación con la equidad de género: la necesidad de que las tareas de cuidado incluyan a los hombres. La ausencia de referencias a la situación de discriminación que soportan las mujeres, y la imprescindible corresponsabilidad de los hombres en el trabajo de cuidados son algunas de las razones por las que la ley no ha alcanzado la expectativa (quizá en cierto modo ilusoria) de redistribución igualitaria de las tareas de cuidado ni de liberación de las mujeres de los roles tradicionales. El objetivo de igualdad de oportunidades puede resonar a género, por la simple razón de que se ha utilizado en otras ocasiones del mismo modo (Ley 51/2003, de 2 de Diciembre, de igualdad de oportunidades; Ley Orgánica 3/2007 de 22 de Marzo, para la igualdad efectiva de mujeres y hombres) pero se puede considerar más bien como un simple recurso estratégico-discursivo para presentar y legitimar la ley, que no apunta a una verdadera posibilidad de incrementar la redistribución de tareas.

Por ello, lo más problemático de la ley es la opacidad en relación al género y la invisibilización de la jerarquía de roles en el espacio de los cuidados. La descripción de la realidad de las cuidadoras mujeres que es sustancial en la responsabilidad de los cuidados en familia se ve desplazada por la idea de "cuidados en la familia", dando por supuesto una responsabilidad "generalizada" o igualitaria de las personas que desempeñan las diversas tareas y responsabilidades.

Se constata la ausencia de mecanismos posibles para incidir en la transformación de las responsabilidades de los hombres, en su implicación futura en las tareas. En la aplicación de la ley no se reconocen ni se contemplan las distintas disponibilidades, predisposiciones, roles, identidades y situaciones de hombres y mujeres en la vida familiar y sus consecuencias. Por el contrario, se hace un supuesto muy genérico sobre los efectos positivos de la ley para las mujeres, que en su momento suscitó expectativas muy altas, pero que aún no se han cumplido. Parecería que la ley se refiere o tendría efectos en un sujeto sin género, no se sitúa en el proceso de reflexión y de ejecución de las competencias de la ley la asimetría de género que siempre ha existido en las tareas de atención a las personas.

cia y su progresiva importancia lleva ahora al Estado a intervenir en este ámbito con la regulación contenida en esta Ley, que la configura como una nueva modalidad de protección social que amplía y complementa la acción protectora del Estado y del Sistema de la Seguridad Social". (LAAD exposición de motivos). 
Sin embargo, la misma noción de dependencia está condicionada por el género. Las exigencias de autonomía pueden ser distintas en función del poder de los sujetos y de la percepción personalizada de sus necesidades. Los varones mayores que enviudan pueden ser dependientes y exigir la realización de las actividades domésticas simplemente por el hecho de que no saben como enfrentarse a ellas, ya que nunca las han realizado (Pérez, 2006).

Esta opacidad frente al género afecta tanto a la realidad actual como a la perspectiva de futuro a la que apunta la ley. De este modo, más que a transformar la redistribución de roles de género en el cuidado, puede contribuir a reproducirlos, acentuando la brecha entre varones y mujeres. La "aniquilación simbólica" del reconocimiento de la labor de las mujeres en las tareas de atención y el agravamiento de su situación se refuerza más aún cuando ésta se sitúa bajo otras categorías que se establecen en la LAAD como "cuidados no profesionales" o "cuidados realizados por personas de la familia o de su entorno o no vinculadas a un servicio de atención profesionalizada". Se ha encontrado que las mujeres representan el $84 \%$ de los cuidadores, y una gran parte de las mismas mantiene una relación de parentesco con la persona dependiente (IMSERSO, 2005a). En función de esto resulta llamativo que estos datos no se reconozcan explícitamente, sino que se minimicen en la redacción de la ley, lo que tiene efectos prácticos con relación al mantenimiento de la desigualdad. La desigual distribución de las tareas se hace patente también en los datos oficiales sobre cuidadoras y cuidadores, incluso en los más recientes. Según los últimos datos proporcionados con relación al Sistema para la Autonomía y Atención a la Dependencia, actualizados a1 de Mayo (SAAD-IMSERSO,2012), el número de convenios especiales a cuidadores no profesionales de personas en situación de dependencia a partir de la puesta en marcha de los convenios vinculados a la prestación económica en el entorno familiar era de 12.995 para los varones y de 163.534 para las mujeres.

El discurso de algunos actores clave corrobora que la situación que experimentan las mujeres, incluso los dramas que habitualmente viven las mujeres cuidadoras de familiares en sus domicilios, no se han visto representados en la ley, y consideran que se deben a varias causas, entre ellas: la ausencia de las protagonistas por sus dificultades de movilización social, la discriminación de las mujeres en los espacios de participación política o la utilización de otras vías y canales de representación.

La situación terrible de las mujeres cuidadoras no se ha trasladado, porque es un problema que vive cada mujer en su casa. Si en España hubiera existido una Asociación de mujeres cuidadoras, esto se habría adelantado muchos años, pero no ha habido una presión social de mujeres cuidadoras, ha sido un tema interiorizado en las familias (...) (Exdirector del IMSERSO y experto en mayores y protección social).

Hay una cierta capacidad de presión que no se le quiera dar ese rango de interlocución, porque en general a las organizaciones de mujeres nos consideran menores de edad politicas, es decir, nos consideran con poca capacidad 
política. Yo siempre les digo que me parece igual que cuando el debate del voto de Clara Campoamor (...) (Representante del Forum de Política Feminista).

Se convierte pues en un mecanismo tímido e híbrido, cuyos objetivos se plantean como liberadores, y que promueven la protección y la igualdad, pero que no interviene de forma eficaz y decidida en los mecanismos de transformación de la situación, al menos en el ámbito de las diferencias de género de los cuidadores. No atiende ni promueve herramientas para eliminar los obstáculos que se oponen a la materialización de la igualdad en las situaciones concretas. Parece dar por supuesto una redistribución justa de los cambios, una redistribución automática puesto que no reconoce las resistencias sociales al cambio, en concreto a la incorporación de los hombres en la tarea del cuidado, ni los efectos del poder diferencial y del desigual acceso al trabajo de hombres y mujeres. En último término son las familias, mejor dicho las mujeres de la familia, las que tienen que decidir en cada situación.

La consecuencia es una versión más de lo que ha ocurrido con el "reparto" por sexos del trabajo doméstico en su conjunto: en vez de implicar a los varones en las tareas del hogar, ha diversificado las categorías del trabajo de las mujeres, estableciendo escalas de importancia y remuneración entre ellas. Las prestaciones económicas que concede la ley son un medio de que una mujer pague a otra mujer en la que delega las tareas de su rol femenino. Este mecanismo no sólo no redunda en equidad entre hombres y mujeres, sino que produce una diferenciación "escalar" de las mujeres (Serrano y Artiaga, 2012). La estructura de los cuidados dentro del ámbito familiar suele ser jerárquica y de poder distribuido entre diversas mujeres : El primer nivel de la jerarquía lo ocupa una mujer ligada por parentesco al dependiente que es la responsable, y los siguientes niveles otra $u$ otras remuneradas que se ajustan a las condiciones decididas por la primera. Fuera del ámbito familiar el cuidado se estructura asimismo en un orden jerárquico femenino en cuyo primer nivel están las mujeres expertas o técnicas y en un segundo nivel las mujeres simplemente "cuidadoras". A medida que el nivel es más bajo, la carga de trabajo es mayor y también lo es su invisibilidad y la indefinición de las tareas.

Tiene también muchos agujeros negros ¿no? Lo de la libertad de elección. Sobre todo, porque la libertad, no hay tal libertad de elección, puesto que no hay elección. Es... Los recursos escasísimos o un "dinerito" escasisimo también, en el fondo, para que tú pagues a otra mujer, que es una cuidadora inmigrante, normalmente, eh. O sea, como ves, todo eso es una especie de espiral que tiene un grado, en mi opinión, de perversión bastante importante. Lo cual no quiere decir que no valore la ley como un avance histórico que ha sido. (Extrabajadora del IMSERSO y experta en cuidados en el entorno familiar)

La realidad es que la ley promueve ocupaciones profesionales de bajo nivel y de escaso reconocimiento social, y sobre todo, en línea con los roles tradicionales. De ahí la polémica suscitada con relación al Art. 18 de la ley. Muchas organizaciones feministas no estaban de acuerdo con su contenido, ya que se refiere a la prestación 
económica para cuidados familiares ${ }^{5}$. La implementación de dicho contenido podría tener o haber tenido incluso efectos perversos: reforzar los roles tradicionalmente femeninos a cambio de una bajísima remuneración y condiciones laborales inferiores.

"estamos condenando a señoras a permanecer en casa por 400 y pico euros, 24 horas al día, 365 días al año (Representante de la patronal, AESTE)

La escasez de los recursos económicos asignados para este cometido limita la otra parte necesaria de la transformación de los roles de género: el que los varones se integren en esa esfera de la vida familiar. Dada la brecha salarial de género, que perjudica a las mujeres, y la mayor calidad y valor social de los puestos que el mercado de trabajo dispone para los varones, es muy improbable esperar que éstos se interesen y se impliquen en una tarea ciertamente distante de su identidad de género y tan mal pagada.

Me parece que es una racanería el haber creado una base inferior a la minima exclusivamente para este grupo de personas que además por los datos estos que ya confirman lo que preveiamos, que el 95\% son mujeres porque ningún hombre está dispuesto a trabajar a jornada completa por $400 €$ al mes (Representante del Forum de Política Feminista).

Por ello, la eficacia de la ley será muy limitada si no se acompaña con otros elementos que incidan en el cambio, que no es únicamente la mejora de la situación económica. En base a su formulación, simplemente se espera que al aumentar los recursos económicos destinados a la misma se incida sustancialmente en la situación de las mujeres en la igualdad de tareas. Aunque muy popular y difundida, la idea de que el progreso económico resolverá la desigualdad no es sino una estrategia retórica, que desvía el fondo de la cuestión y que ha sido sistemáticamente utilizada como justificación para no desarrollar mecanismos específicos de transformación de todas las desigualdades. De acuerdo con Saltman la equidad no depende del progreso sino de la redistribución social de los recursos, cuestión en la que se ponen en juego las luchas de poder entre los diversos grupos y estamentos sociales (Saltman, 1992). La promoción de una redistribución social de los cuidados no sólo es cara, sino que es compleja y además tropieza con exigencias de gestión y con diversas resistencias, que serán expuestas más adelante.

${ }^{5}$ Excepcionalmente, cuando el beneficiario esté siendo atendido por su entorno familiar, y se reúnan las condiciones establecidas en el artículo 14.4, se reconocerá una prestación económica para cuidados familiares (Ley 39/2006). 
(...) La intención de la ley es que haya, desde la perspectiva de género, un cambio sustancial, no sólo una prestación económica. Pero todo esto es más caro, más complejo, exige más gestión (Exdirector del IMSERSO y experto en mayores y protección social).

Podemos decir que la LAAD articula un discurso "moderno" en torno a la necesidad de nuevos modelos de protección social, la incorporación de las mujeres al mercado de trabajo, etc. y que supone un cambio de carácter simbólico en relación con la desigualdad de género, en tanto en cuanto se reconoce el papel que juegan las mujeres en la reproducción de la vida. Sin embargo, esto es un hecho que no se puede obviar por la evidencia tanto numérica como de condiciones de explotación que viven muchas mujeres. A pesar de ello, se ha puesto en cuestionamiento que la formulación de la LAAD señale problemas y articule propuestas que transformen la organización social en torno a los cuidados y el reparto de éstos entre hombres y mujeres. En esta Ley, lo que se problematiza es más bien la creciente demanda de cuidados, por la que los estados se han visto obligados a poner en marcha medidas, que en muchos casos van en detrimento de las condiciones de vida de las personas que cuidan, ya que no frenan sino que promueven la precarización de estas tareas, así como la perpetuación del papel de las mujeres en estas actividades que son la forma más extendida de explotación en el ámbito del hogar.

\section{Los cuidados como carga o responsabilidad a pesar de la LAAD: una tarea para mujeres, migrantes y/o precarias.}

Evaluar los efectos de una nueva normativa en la realidad resulta extremadamente complejo, sobre todo cuando afecta a tantos aspectos y dimensiones de la realidad, como es el caso, y cuando además, en los primeros años de su implantación se experimenta una crisis económica. Asimismo, el escaso periodo de tiempo que ha transcurrido desde que se publicó, en el 2006, dificulta el análisis sobre la repercusión de la Ley. Una breve mirada a las estadísticas disponibles nos permite apuntar algunas "pinceladas" de un panorama poco optimista sobre la incorporación de los varones y la redistribución de las tareas de los cuidados en la sociedad.

Previamente hay que subrayar la dificultad de comparación de los datos globales, ya que las estadísticas son muy pormenorizadas en algunos casos, por comunidades autónomas o por tipos de dependencia concretos, y es difícil registrar el cómputo global. Sin embargo, no sólo los datos sino también las conclusiones de los diversos investigadores revelan una realidad muy feminizada. A lo largo de los últimos 20 años el modelo del cuidado es familiar y femenino, se realiza mayoritariamente en el domicilio familiar y es llevado a cabo por mujeres. No obstante la evolución producida a lo largo de estas últimas dos décadas, y sobre todo tras la LAAD, ha ido hacia la desvinculación de lo familiar con relación a los cuidados y menos intensamente hacia la incorporación paulatina de los varones. Según la Encuesta sobre la Soledad de las Personas Mayores (CIS, 1998), si en 1998 sólo en un 2,6\% 
de los casos, el cuidador/a principal era una persona que no tenía vínculos familiares con el sujeto que recibe los cuidados, en 2004 el apoyo externo a las familias era ya alrededor del 15\% (Fundación Edad y Vida, 2004), aunque los cuidadores familiares seguían siendo mujeres casi en su totalidad. Como ya se había descrito previamente, en el 2005 las mujeres representaban el $84 \%$ del universo del cuidador y una gran parte de ellas eran parientes directos, el 50\% hijas de la persona dependiente, un $12 \%$ esposas o compañeras y un $9 \%$ nueras. Los parientes directos varones participaban en una proporción casi testimonial: el $8 \%$ eran hijos, el 5\% esposos y $2 \%$ yernos. El 7\% de los cuidadores compartían la atención de las personas mayores con las empleadas de hogar (IMSERSO, 2005a). El empleado/a de hogar que cuida es en una amplia mayoría mujer $(96,6 \%)$, sólo el 3\% de este colectivo son hombres, según la encuesta sobre empleados y empleadas del hogar que atienden a las personas mayores, realizada en 2004 por el IMSERSO (2005b).

Diversas encuestas y estudios recientes (Martín y Rogero, 2010, Rodríguez et al. 2011, por ejemplo) revelan que en las familias se ha producido una incorporación importante de cuidadores/as procedentes de fuera del ámbito familiar. Si bien es cierto que se mantiene el predominio de la responsabilidad familiar, éste se complementa con la presencia de los foráneos. El trabajo de los foráneos suele ser muy intenso. Según la Encuesta sobre Discapacidad, Autonomía personal y Situaciones de Dependencia (INE, 2008), el 80\% de las empleadas de hogar inmigrantes que trabajan como cuidadoras principales de personas mayores lo hacen entre 6 y 7 días a la semana durante una media de 15,7 horas por día. Otros estudios aportan resultados que van en la misma línea (Martín y Rogero, 2010, por ejemplo). Es una constante histórica el que los grupos (mujeres en este caso) menos poderosos o más desprovistos de recursos (las migrantes) cuiden a los que tienen recursos, desatendiendo incluso a sus propias demandas familiares (Razavi, 2007). De hecho, en los países del sur de Europa con servicios sociales escasos y una mayor tendencia a las transferencias monetarias, se está gestando un sector de mercado laboral precario y unas condiciones de empleo similares a las que se dan en el caso británico (Recio, 2009). La escasez de servicios se está solucionando en gran medida mediante la contratación de mujeres inmigrantes (Bettio, Simonazzi y Villa, 2006; Simonazzi, 2009), que en muchos casos experimentan problemas de semiesclavitud, por la precariedad de los empleos, las exigencias de las políticas de inmigración, y las consecuencias derivadas de las cadenas globales de cuidados.

Volviendo a la red familiar, la figura que adquiere el máximo protagonismo es la de la hija, ya que es cuatro veces superior el porcentaje de cuidados recibidos de hijas con relación a los que se reciben de los hijos. También es superior la ayuda recibida de hermanas en comparación a los hermanos, de nueras frente a yernos $o$, en general, la que se recibe de otras mujeres de la familia en comparación a la que se recibe de otros hombres. Se constata también así una asimetría de género entre dar y recibir cuidados. Incluso en el caso de la relación de ayuda mutua que implica la relación conyugal, por ejemplo, en Andalucía se halló que los hombres de 65 años o más reciben muchos más cuidados de su cónyuge que las mujeres de esa misma edad (29,6\% y 9,4\%, respectivamente) (Portal de mayores,2007). 
Además, los varones cuidadores cuidan a personas más jóvenes (frecuentemente a sus esposas o hijos) y las mujeres a personas más mayores (a sus esposos u otros parientes) (IMSERSO 2008). En casos particulares la pauta se repite, por ejemplo, según la encuesta EDAD (INE, 2008) el perfil típico de la cuidadora de personas con discapacidad o diversidad funcional es una persona en edad laboral, de entre 45 y 64 años, y por cada hombre de hasta 64 años que realiza estas tareas hay cuatro mujeres que lo hacen. Sin embargo en el colectivo de más edad (mayores de 80 años) los porcentajes de cuidadores y cuidadoras son casi los mismos. En general, parece encontrarse que el prototipo de mujer cuidadora es una mujer en edad laboral (algunas de ellas incluso en situación de actividad) que cuida a sus padres, en cambio, el prototipo de hombre cuidador es un varón en edad de jubilación que cuida a su esposa.

Resulta interesante, la diferencia de edad de los cuidadores y las cuidadoras. En general, con relación a la edad, las mujeres cuidadoras son más jóvenes que los hombres, la edad media se sitúa en pleno periodo laboral (54 años). La de los varones, en edad de jubilación (67 años). Es decir, los varones se pueden incorporar al cuidado al final del periodo de su vida laboral, mientras que para muchas mujeres ocupa una sustantiva parte de su tiempo de "ocupación" profesional.

Descendiendo al análisis de las actividades y tareas que se realizan, los resultados muestran que la frecuencia y el tiempo dedicados por las mujeres a cuidar son mayores que los de los hombres. Más de dos tercios de las mujeres cuidadoras proporcionan cuidados permanentes, frente a la mitad de los hombres, y afrontan cargas elevadas de cuidado con más frecuencia que ellos (Rodríguez et al., 2004). La variedad y la complejidad de las actividades es mayor en las mujeres, especialmente en las de bajo nivel socioeconómico (Larrañaga et al., 2008). En consonancia con la diferencia de tareas y de tiempo de dedicación, es mayor el porcentaje de mujeres que experimentan niveles de sobrecarga intensa ( $74 \%$ frente al $45 \%$ de los varones) (Portal de Mayores, 2008)

En resumen, los rasgos más sobresalientes de esta realidad son la familiarización del cuidado a pesar de que se aprecia un cada vez mayor encargo a personas externas a la familia y la feminización de las tareas. En conjunto el cuidado se mantiene con unos perfiles de género muy diferenciados marcados por la edad, las tareas a realizar, las implicaciones en la inserción profesional y las dimensiones afectivas.

Los datos confirman que en la tarea de cuidados que reflejan las estadísticas se observa que la responsabilidad de los cuidadores es muy amplia, que se atienden necesidades que requieren una fuerte implicación, y que la intensidad del tiempo y del esfuerzo del cuidado es muy elevada. También se confirma la relevancia de la desigualdad de status (tanto por cuestión de género, clase u origen), ya que es precisamente en los niveles socioeconómicos inferiores en los que las mujeres se hacen cargo y se responsabilizan más de los dependientes, y es sobre ellas donde recae el mayor coste de tiempo y el mayor coste psicológico del cuidado.

Algunos aspectos más cualitativos que no aparecen en las encuestas, se apuntan en las entrevistas realizadas a los actores que tuvieron importancia en la formula- 
ción de la LAAD. A continuación se recogen los aspectos que se consideran más destacados:

- Los hombres se incorporan al cuidado en situaciones más extremas, cuando no tienen más remedio. Cuando sus familiares directos, esposas o hijos/as, no pueden hacerlo por sí mismos, por ejemplo, y cuando carecen de recursos económicos.

- A estos hombres, que suelen ser jubilados, se les valora mucho socialmente, concretamente se valora su abnegación o su dedicación, su sufrimiento y el esfuerzo que han hecho por desempeñar correctamente una tarea que no se les supone adecuada a su rol masculino. No ocurre lo mismo con las mujeres que se han dedicado al cuidado. Sus tareas no se valorizan tanto, ni se tiene en cuenta que han perdido o ponen en riesgo la realización de otras actividades (personales o laborales), se naturaliza su disposición para cuidar.

- Un porcentaje no desdeñable de emigrantes hombres sin papeles se han sumado al cuidado, sobre todo al cuidado de hombres. Estos emigrantes no aceptan trabajos tan mal pagados como los que aceptan las mujeres emigrantes, sino que tienden a buscar trabajos mejor pagados y mejor valorados. El cuidado empieza a ser un nicho de mercado interesante para hombres emigrantes en residencias de ancianos, principalmente para cuidar a otros hombres.

\section{Perspectivas de futuro en la redistribución de los cuidados y el género: obstáculos estructurales y psicosociales}

Parece que el camino recorrido hacia el reparto y la valorización de los cuidados en este contexto no es lineal. Se está produciendo un proceso de lenta desfamiliarización, pero la feminización no ha experimentado un avance sustantivo, incluso se apunta hacia un retroceso, al menos en los cuidados familiares. Además, ahora son otras mujeres de estratos sociales inferiores (mujeres migrantes, por ejemplo), las que se hacen cargo de estos cuidados. Las resistencias a la puesta en marcha de iniciativas que promuevan la transformación de la organización social en torno a los cuidados, junto con las condiciones externas de las diferentes situaciones económicas y las luchas de poder entre los diferentes grupos sociales pueden estabilizar los avances o producir periodos de retroceso.

Además de sus deficiencias internas, la puesta en marcha de la ley de dependencia ha tropezado con obstáculos estructurales y con una coyuntura económica desfavorable. Por ejemplo, en el 2004 se estimaba que había el equivalente a 90.000 puestos de trabajo a tiempo completo dirigido al cuidado de personas dependientes y se estimó que para el 2010 con la LAAD habría en torno a 350.000 empleos en el sector (Herce, Labeaga, Sosvilla y Ortega, 2006). Las cifras actuales muestran que aunque ha aumentado el empleo en el sector, éstas se alejan de las previstas, fundamentalmente debido al retraso en la implantación de la ley y porque las presta- 
ciones económicas para los beneficiarios se dirigen mayoritariamente al cuidado en el entorno, lo que ha propiciado un escaso desarrollo de los cuidadores profesionales (Herrera, Martín, Bello, Muñoz y Sitges, 2011).

Sumado a todas estas circunstancias, persisten importantes barreras a la redistribución de las responsabilidades del cuidado coherentes con las que siguen perpetuando la desigualdad profesional. Nos referimos principalmente a tres: a) los recursos económicos destinados al cuidado y por tanto, los salarios, b) las condiciones del trabajo, y c) las repercusiones del trabajo en la identidad profesional y social.

Los recursos son insuficientes $\mathrm{y}$, como consecuencia, no hacen posible una retribución justa en relación a la tarea ejercida, lo cual conduce a que los hombres no los acepten. Los salarios deben proporcionar a los cuidadores una cierta capacidad económica y ser atractivos para todos. En caso contrario, sólo las mujeres, que son las que tienen más dificultades de acceder al mercado laboral, especialmente en condiciones de crisis, aceptarán estos trabajos.

Entonces, los salarios tienen que ser dignos. Tenemos un 10\% de trabajadores pobres, casi todo mujeres. (....). Entonces claro, hay que cambiar las condiciones en el mercado de trabajo, sobretodo para las mujeres, porque si no la cosa está muy clara. Y un día la gente prefiere antes vivir con menos y libremente, que estar sometida a la compulsión indisciplinaria de un mercado de trabajo, que sobretodo en los segmentos menos cualificados es de una dureza casi del siglo XIX, (Experto en mayores y protección social, participa en el Libro Blanco)

Además de la retribución adecuada, es fundamental el cambio de las condiciones de trabajo como cuidador/a y una mayor definición de los cometidos. De acuerdo con el modelo maternal del cuidado (dependencia muy estrecha entre cuidador y cuidado y actividades de auxilio personal) que sigue estando presente como eje ordenador de las tareas (Tobio et al., 2010) el rol cotidiano del cuidador/a es en realidad una mezcla en general poco concreta y especificada de tareas profesionales $\mathrm{y}$ de atención a necesidades afectivas. Algunas de las tareas que implican un trabajo emocional son la atención al cuerpo del dependiente, la relación con el sufrimiento, con el pudor, con la intimidad física, con las necesidades de limpieza, contacto o relación afectiva, con la dignidad como sujeto humano. En este aspecto, la socialización de los hombres y las mujeres ha sido muy diferenciada, y las resistencias y falta de familiaridad de los hombres es tan acentuada como la afinidad y naturalización con que la ejercen las mujeres.

Por otra parte, este trabajo no redunda, o redunda muy escasamente, en la identidad profesional del cuidador/a para su futuro. Mientras siga siendo un tipo de trabajo no especializado, confundido con las atenciones maternales o con las obligaciones morales de las personas, permanecerá invisibilizado, privado de cualificación y será muy poco útil para la promoción profesional futura de los/as cuidadores. La poca visibilidad que se da a los cuidados como necesidad social tiene graves repercusiones para muchas mujeres que han ocupado en ello gran parte de su perio- 
do laboral activo, ya que no parece servirles para reinsertarse de nuevo en otro tipo de trabajo y quizás tampoco en el mismo. Por ello, es de esperar que continúe la pauta de que los varones se resistan a ejercer este trabajo durante su periodo activo, ya sea por mejores expectativas de otro trabajo o por la dificultad de rentabilizar las aptitudes y la cualificación adquiridas en otra actividad. En este sentido, una posibilidad de incidir en la implicación igualitaria de los hombres y las mujeres sería el reconocimiento explícito de la cualificación que conllevan los distintos tipos de cuidados, para que se pueda reciclar o utilizar en la vida profesional futura de los trabajadores, por ejemplo. Nos enfrentamos entonces al arriesgado ejercicio de traducir la actividad al ámbito del recuento, de lo mercantil, de lo profesional para establecer la correspondencia y la comparación con el valor de otros trabajos, distanciándolo así de la subjetividad del "cuidador" y del "cuidado", reduciéndolo a meros "servicios" cuando se sustenta en dimensiones tan importantes como la responsabilidad, la inevitable afectividad y la dignidad subjetiva. Por el contrario, otra opción para fomentar la redistribución de las tareas de cuidados iría por el camino de valorizar la relación interpersonal afectiva como un componente sustancial de este trabajo, con las dificultades que supondría evaluar dicha dimensión.

Es necesario, por otra parte, el reconocimiento social del papel de cuidador varón, ya que de acuerdo con las concepciones tradicionales de la masculinidad y feminidad, el cuidado no sería coherente con la masculinidad hegemónica. La presencia de los estereotipos de género asociados a una diferencial valoración son factores que pueden tener una fuerte capacidad operativa de resistencia al cambio. Un varón tradicional podría aceptar el rol de experto, de especialista o de profesional en las tareas de cuidado, pero le resultaría más difícil aceptar los trabajos de cuidados más "inespecíficos" o maternales, ya que, podría generar malinterpretaciones y desvalorización de su identidad masculina.

Pese a todo, el número de varones cuidadores parece que se va a incrementar a juzgar por lo que ocurre en varios países (Crespo y López, 2008; Kramer, 2002; Rivera, 2001; Ribero, 2005; Thompson y Kramer 2005). Y según la opinión de las personas empleadas en este sector, que aprecian un cierto cambio de sensibilidad. Los hombres se empiezan a ofrecer a hacerse cargo de niños y de ancianos. Cada vez es mayor el volumen de hombres que están trabajando en este tipo de actividades, debido sobre todo a las consecuencias de la actual crisis económica que ha dejado a muchos de ellos en situación de desempleo. Pero no es menos cierto que esta tímida iniciativa, más coyuntural que estable, coexiste con una resistencia importante de la mayor parte de las familias a contratar hombres dentro del hogar (Observatorio de Empleo Navarro, 2009).

No obstante, conviene no caer en lo que se ha llamado el efecto de tokenismo (Apfelbaum, 1999) que consiste en tomar un simple señuelo como índice de una transformación en el orden de las responsabilidades sociales. Un pequeño incremento en una cierta dirección no significa la constatación del cambio hacia la reformu- 
lación de los géneros ${ }^{6}$. Por otra parte, la dinámica de la evolución de la equidad no suele ser un proceso continuo, sino sujeto a movimientos de conflicto, de retroceso o de recomposición según los avatares económicos o el poder de los grupos implicados en el cambio (Saltman, 1992).

La trayectoria de la redistribución de papeles tropieza asimismo con una serie de obstáculos psicosociales, que operan desde el interior de los sujetos cuidadores y cuidados, y que no se deberían descuidar en la formulación política de ningún proyecto de cambio. Para la mayoría de las personas, este trabajo sigue vinculado a la dimensión moral de obligación y ha sido asignado tradicionalmente a las mujeres, es por ello por lo que no ha dado el salto a la consideración de trabajo profesional con cualificación, válido e intercambiable por dinero en el mercado de trabajo. A pesar del cambio de actitudes que sin duda se ha producido, la actitud de naturalización de las tareas es tan espontánea como fuerte y resistente y opera delegando en la práctica cotidiana la mayoría de las funciones del cuidado a las mujeres.

Todavía la mujer sigue siendo la cuidadora principal en la cadena de cuidados, y que eso va a llevar mucho tiempo, es un problema de tiempo, es decir, incluso los mismos hombres que tienen claro que hay que hacer una distribución equitativa de los cuidados siguen mirando a la mujer, como lo harán mejor que yo, siempre lo ha hecho así, yo soy un manazas, por lo tanto, siguen asignando el rol a la mujer, le da miedo, viven del (...) bueno, pues que lo hagan quiénes lo hacían. Entonces, mentalmente, sí, en términos prácticos no (Experto en mayores y protección social, participa en el Libro Blanco).

La naturalización de las tareas del cuidado opera aún incluso en los hombres que hacen un esfuerzo por ser igualitarios y entrar en la vida familiar y los roles nutricios y del cuidado. El trabajo de Covas (2009) sobre "hombres igualitarios" y muchos otros muestran que les parece lo más natural que las mujeres sean solícitas $\mathrm{y}$ atentas a la necesidad de los otros, hasta el punto que manifiestan que sus esposas sufren cuando ellos están enfermos, les animan y acompañan al médico, asumen de forma natural estar pendientes de los medicamentos, ayudan a que el enfermo se ponga a dieta o controlan y fuerzan a tomar los medicamentos, a descansar y a cumplir los hábitos aconsejados por el médico.

Pero esa naturalización no sólo opera en los hombres. Muchas mujeres la comparten, ya que es una parte sustancial y determinante de la identidad femenina tradicional. Si en los hombres opera como delegador natural de tareas, en las mujeres opera autoimponiéndose una obligación y asumiendo la culpa en caso de no

${ }^{6}$ Podemos ejemplificar este efecto en multitud de situaciones, el incremento de mujeres en el ámbito laboral no significa la igualdad, el que los niños aprendan a coser o planchar en las escuelas no significa la igualad en la educación, el que las niñas puedan hacer deportes antes solo masculinos, como el futbol, no significa la igualdad en el deporte, etc. 
realizarla, frenando espontánea e imperceptiblemente la intervención del estado u otros agentes sociales en la tarea del cuidado. Así lo reconoce una de nuestras entrevistadas:

Tú dime qué mujer, feminista o no feminista, va a defender, en donde, el que "yo tengo un hijo con discapacidad, libéreme usted de esto". Va a defender otras cosas. Y, en el caso de los viejos, hay que defender los servicios, nuestra liberación, pero también están ahi ¿vale? Y forma parte de nuestra vida, nuestra historia y seremos nosotros, dentro de un tiempo (Extrabajadora del IMSERSO, experta en cuidados en el entorno familiar)

Conviene estar atento y aprovechar los posibles mecanismos de cambio, por mas sutiles que sean.Covas (2009) señala una serie de dimensiones que transforman los valores de los varones hacia la violencia machista, algunos de los cuales nos parecen comunes a los que pueden afectar a la valoración del rol nutricio y cuidador. La toma de conciencia, ya sea por su participación social, su experiencia de trabajo o la influencia de mujeres parejas o compañeras con valores igualitarios, puede ser el primer paso. La relación con mujeres igualitarias, aunque sea en muchas ocasiones molesta, resistente y provocadora de inseguridad, suele ser un factor decisivo en la producción del cambio y en la estabilización del mismo. Muchos hombres describen ese proceso de socialización a través de su relación con compañeras sentimentales, que aunque les llevan a establecer relaciones exigentes, éstas les resultan enriquecedoras y satisfactorias. Tampoco es despreciable el papel que puede cumplir el cambio forzado, es decir, la necesidad de asumir determinadas tareas, bien sea por necesidad o por la amenaza de perder las relaciones amorosas si no se produce el cambio. De nuevo, en este caso el papel de las mujeres firmes en el mantenimiento de la igualdad y en la defensa de sus derechos es un agente de transformación social muy importante. No debemos despreciar el cambio que se pueda producir por la pura necesidad de asumir roles, el cambio forzado. Gerson (1994) observa un incremento de la implicación de los varones en las tareas domésticas con el paso de los años a medida que se ven obligados a hacerlas. Estos datos parecen indicar que las experiencias y circunstancias de las personas en su edad adulta tienen un poder explicativo más fuerte en sus elecciones vitales que el rol de género aprendido en el proceso de socialización (Risman, 1998).

En todo caso, el incremento del número de cuidadores varones, sea por necesidad o por influencia de las mujeres incidirá en la valoración progresiva del rol de cuidador para ellos y en la socialización para ello de otros hombres. En la fragmentación de las relaciones familiares y laborales se puede encontrar una fuente de conflicto de roles y una reconstrucción transformadora de las masculinidades, que pueden reducir sus resistencias a su incorporación a este trabajo. Aunque no seria suficiente y habría que implementar mecanismos sociales educativos, motivadores o de refuerzo a sanción para que se produjera un efecto notable y duradero. Pero cuando los hombres reconstruyen su identidad y aceptan desempeñar funciones tradicionalmente femeninas se encuentran frecuentemente con la falta de legitimi- 
dad social de sus acciones. El trabajo de Laura Merla "no trabajo y me siento bien" (2006) explicita magistralmente las estrategias de los varones para defender el rol de padre en casa y minimizar el impacto de las reacciones negativas que le devuelven los otros hombres, pero también las mujeres, cuando realizan las tareas especificas de este rol. Los hombres deben transformar la definición de sí mismos, sus presentaciones en público, controlar la información que transmiten sobre el ejercicio de sus tareas y su significado y tener mucho cuidado con no desvincularse totalmente de las prácticas masculinas de trabajo. Por ejemplo, en cuanto a las definiciones de sí mismos, pueden asumir una actitud desafiante que les presente como totalmente discordantes con la masculinidad hegemónica, o bien negar que se desmarquen del rol masculino o argumentar que sólo lo hacen temporalmente y por razones coyunturales. Cada una de las tres estrategias conlleva un trabajo de discurso y un coste personal de observación de las reacciones de los otros y de redefinición. Un trabajo similar o aún más costoso es el que se hace para limitar el impacto de las reacciones negativas. Las personas pueden proyectar en estos padres identidades negativas, como parado, asistido o inválido, con lo que para defenderse pueden verse impelidos a controlar la información que se transmite, a rechazar a los detractores o a disculparlos buscando las razones de sus comentarios o malas interpretaciones. Finalmente, es común que estos padres en casa muestren que conservan alguna actividad que pueda ser presentada como profesional, aunque no sea remunerada, pero que muestre que no ha perdido la vinculación con el mundo del trabajo masculino. Así mantienen una forma de identidad múltiple, como estrategia defensiva de su legitimidad. La necesidad de usar estas estrategias muestra la dificultad de aceptación social de la transformación de identidades, pero a la vez pueden ser un recurso para mantener las nuevas identidades.

El trabajo de cuidados, sobre todo el de las personas mayores, genera por si mismo muchas resistencias internas en los posibles cuidadores, tanto en hombres como en mujeres. Los múltiples trabajos sobre los costes emocionales del cuidado ponen de manifiesto actitudes negativas, que muy frecuentemente implican tristeza y desagrado. Se ha insistido mucho en ellas, quizás demasiado, así como en los efectos emocionales negativos, pero también se han expresado valores y satisfacciones intrínsecas a la tarea. Algunas aportaciones apuntan ciertos efectos positivos que el cuidar a mayores produce en las personas cuidadoras (Nolan, Grant, Keady, 1996). Cohen et al. (2002) muestran que el $75 \%$ de cuidadores pudieron identificar un aspecto positivo (compañía, recompensa, diversión, obligación y sentido de la experiencia, por este orden de importancia). La satisfacción es la segunda motivación de los cuidadores según una reciente investigación en España. También se incluye como motivo la dignificación personal y la relación positiva con el dependiente, sobre todo cuando es alguien ligado por parentesco (Tobio et al., 2010). Las trabajadoras de geriátricos no vinculadas directamente a los dependientes pueden encontrar una recompensa positiva en el cuidado de otros por la identificación con los familiares (quererlos como a padres o madres), pero también consideran que aprenden o incluso se previenen con el conocimiento para anticipar sus propios problemas en la vejez (Rodrigues, Andrade Marques, 2001). La satisfacción con el 
trabajo depende, entre otros factores, de sus condiciones y de la libertad con que se elige, que son muy precarias. Pero aun así, cabe concluir que "cuando el cuidar se hace sin exceso y por elección propia es una experiencia positiva. El cuidado de las personas es entonces una actividad más de la vida si se ejerce con unas condiciones dignas, con descanso diario, vacaciones, horario limitado, reconocimiento y ayudas" (Tobio et al., 2010: p. 137).

En la reducción de resistencias y obstáculos internos a la tarea de cuidados cumple una importante función, no sólo reconocer la importancia social que tiene, sino la valorización de las destrezas y conocimientos que se adquieren en el ejercicio del cuidado y que pueden incidir no sólo en su adecuada realización, y en su posibilidad de utilización en otros contextos y situaciones. No se puede tener en cuenta sólo su valoración moral, su valor de responsabilidad, o su valor mercantil. Habría que insistir en sus valores de aprendizaje y afectivos. Rescatar así sus posibilidades de atracción. ¿Qué puede tener de atractivo la tarea de cuidar? La respuesta a esta pregunta puede ser analizada al menos en base a tres dimensiones: la cognitiva, la afectiva y la moral.

En cuanto a la dimensión cognitiva, el trato con dependientes genera un saber susceptible de ser utilizado en las relaciones interpersonales, ya que éste se puede transferir de unas relaciones a otras. Se trata de un saber de carácter psicológico, centrado en las reacciones, afectos, demandas y maneras de conseguir el bienestar humano, que debería tener un mayor reconocimiento que el que tiene en la actualidad. Sumado a ello, el cuidado a otros también puede servir como preparación o socialización anticipatoria de la vejez, lo que no sólo podría considerarse parte de esa dimensión cognitiva sino que también tendría un claro componente terapéutico.

Sobre la dimensión afectiva hay que insistir en la importancia de los vínculos de reconocimiento interpersonal y afectividad con otros seres humanos que implica el cuidado.

Los aspectos morales son bien conocidos, ya que están en la base de las decisiones políticas y personales. No obstante, el imperativo moral de asumir la responsabilidad sobre los dependientes puede ser tomado desde una perspectiva menos impositiva y más gratificante.

Cuando hablamos de reconocer el valor de los cuidados no nos referimos al "abuso de cuidados" o a una ética del cuidado que no tenga en cuenta las tres dimensiones que señalan Amaia Perez Orozco Silvia L. Gil: el derecho a decidir si queremos cuidar o no cuidar, el derecho a recibir cuidados y la necesidad de incorporar derechos laborales en el trabajo de cuidados remunerado; lo que exige de un reparto y corresponsabilización sobre los mismos (Pérez Orozco y López Gil, 2011).

La relación con los niños, la crianza, que es una de las formas más gratificantes de la atención a dependientes, ya goza de una cierta valoración positiva, y el ejercicio de la paternidad empieza a ser adornado con calificativos positivos, poniendo de manifiesto la ternura, la labor educativa, el aprendizaje de destrezas y el establecimiento de vínculos afectivos "interesantes" para el cuidador. De esta forma, habría que subrayar los aspectos psicológicos positivos de todas las variedades del cuidado, sobre todo si se realiza en condiciones de libre elección. En esas condiciones el rol 
de cuidador/a podría empezar a ser deseable. No olvidemos que el cambio no se produce forzadamente, sino que para ser eficaz y sobre todo duradero debe partir del deseo y la aceptación interna.

Asimismo, la reivindicación de un trabajo digno y el cuestionamiento de la predisposición de las mujeres para los cuidados y su reparto entre hombres y mujeres, deben de ir acompañados, de modo complementario, por un replanteamiento de los paradigmas normativos en torno a cuáles son las necesidades sociales y quiénes deben hacerse cargo de ellas. Existen nuevas voces feministas que plantean que es necesario cuestionarse la dicotomía autonomía/dependencia porque se considera que todas las personas somos vulnerables en algún momento de nuestra vida y no sólo en ocasiones específicas como señala la Ley (en la vejez o si tiene una situación de diversidad funcional). El no reconocimiento de esta vulnerabilidad social y su invisibilidad, producen una desvalorización de las actividades de cuidados que realizan en su mayor parte las mujeres. El sostenimiento de la vida cotidiana, la atención de la salud, la organización del hogar, la implicación emocional, y las tareas materiales que son necesarias en el día a día, se menosprecian y, sin embargo, son claves para la supervivencia humana. Este desprecio unido a la identificación de las mujeres con estas tareas y con "ser para los demás", conlleva que la tarea de los cuidados se plantee como una lógica feminizada y uno de los mecanismos de explotación más ocultos de esta sociedad (Pérez, 2012).

Por ello, es importante que se produzca un cambio de mirada en torno a la cuestión de los cuidados, y que se planteen nuevos paradigmas normativos y de intervención para que los cuidados se sitúen en el centro de la organización social. Lo que plantean estos movimientos es que se produzca una transposición en el orden de prioridades, que sea capaz de descentrar los mercados y de poner las necesidades de las personas y la sostenibilidad de la vida en el centro. Son posturas muy alejadas del feminismo que defiende la "ética de los cuidados", ya que aunque cuestionan el actual orden de prioridades sociales, no hiperidealizan los cuidados, ni los asocian a una esencia femenina; sino más bien, proponen la responsabilidad social y colectiva de atender a esta cuestión que se entiende como fundamental para el mantenimiento de la vida, exigiendo su reparto y resignificación en el orden de jerarquías sociales.

No basta, sin embargo situar el cuidado en el centro de la organización social. Es necesario exigir la redistribución de género de todas sus exigencias, la justicia distributiva en su cumplimiento, la responsabilidad compartida de hombres y mujeres. De lo contrario, no sería más que un ejercicio "inútil" de reasignación de valor sin retribución (si eso fuese posible) a las mismas tareas. La redistribución de la responsabilidad puede ser por si misma un mecanismo de revalorización, y puede ayudar incluso anteceder a la revalorización. Por el contrario, revalorizar sin redistribuir podría dar lugar a una nueva versión de las división del trabajo por sexos, lo cual resulta muy coherente con las nuevas maniobras que alientan la naturalización de la desigualdad y la vuelta de las mujeres a los roles tradicionales promovidas por los sectores más conservadores y algunas voces que remiten a la hiperidealización de la ética de los cuidados y a la atribución esencialista de las mujeres a estas tareas. 
Sin embargo, los actores sociales (académicas feministas, organizaciones feministas y de mujeres cuidadoras y/o trabajadoras domésticas) que apuestan por poner los cuidados en el centro de la organización social, no han tenido una presencia explícita en la elaboración de la LAAD, aunque sí han utilizado otros mecanismos de intervención para filtrar, con un éxito dudoso, sus cuestionamientos sobre el problema de los cuidados a través de diferentes mecanismos de difusión y de presión social (publicaciones, jornadas, encuentros, manifestaciones, etc.).

Entonces, bueno, eso... Luego, también esta el concepto de trabajo; la necesidad de reparto; el cuestionamiento de los tiempos de trabajo y los tiempos para vivir... Bueno, pues todo eso subyace bajo la Ley de Dependencia porque te planteas a qué modelo es al que aspira el cuarto pilar del Estado del Bienestar -como le anunciaban-. Entonces, es un poco, desmontar eso y apostar por otra ley, con otros supuestos y desde otra perspectiva: Implicar más a los hombres... (Asamblea feminista de Madrid).

Las organizaciones de mujeres han propuesto objetivos más a corto y medio plazo en relación con la LAAD. Desde un comienzo, ha existido bastante consenso en los movimientos feministas por abolir el artículo 17 de la LAAD sobre prestación económica a personas en el entorno familiar. Se considera que esta propuesta, reconoce el trabajo de las mujeres pero de forma muy precaria y que además condena a muchas mujeres a seguir cuidando sin la posibilidad de elegir otra cosa.

También ha existido bastante acuerdo (aunque siempre con bastante debate entre posturas más rupturistas y otras más cercanas a la profesionalización como eje central de las demandas), en la necesidad de implementar servicios y de profesionalizar las tareas de cuidados. Aunque en el debate sobre la profesionalización han participado de manera bastante crítica, ya que lo consideran un debate trampa, en los términos en que lo plantea la LAAD.

Nosotras decimos, vale, si se va a profesionalizar que se profesionalice, pero con todas las consecuencias. Con calidad en el trabajo, con reconocimiento, con reconocimiento de experiencia, con cursos de capacitación que te den opción a título y te den opción a entrar a otras posibilidades profesionales. Quiero decirte que si que estábamos de acuerdo, pero claro, no estábamos de acuerdo con lo que se planteaba, que ha quedado en poquísimo; que es que las empresas propias que contratan a la gente te hacen un curso por el que le pagan para que aprendas a cambiar pañales a ancianos y a no sé qué, no sé cuantos; y ya estás capacitada para currar ¿Sabes? Entonces, no creo... No estábamos de acuerdo con eso, aunque sí que estamos de acuerdo en que se profesionalice (Asamblea Feminista).

Ha sido interesante la fusión y complementariedad de las propuestas y debates que se ha dado entre la perspectiva de los movimientos de mujeres y de las voces de los movimientos con diversidad funcional, que han sido muy activos en el desarro- 
llo de la elaboración y la puesta en marcha de la LAAD. En el punto de partida eran posturas que ambas abogaban por el derecho a la "buena vida", pero desde diferentes intereses y puntos de vista. En el caso de las personas del Foro de Vida Independiente, se apuesta por la autonomía personal y de hecho, se propone una figura para posibilitar este objetivo, que es el asistente personal, que finalmente se consigue que se integre en la LAAD. Por otro lado, los movimientos de mujeres proponen que las personas que cuidan puedan decidir si cuidar o no cuidar o si lo hacen, el poder hacerlo con unas condiciones adecuadas. Lo interesante de estas propuestas de transformación social es que los derechos de unos actores sociales no se realicen a costa de los derechos de los otros. De este modo, la suma de problematizaciones y propuestas enriquece el debate, y una experiencia interesante sobre este diálogo es el encuentro, que comienza en 2007, entre el Foro de Vida Independiente y la Agencia de Asuntos Precarios "Todas a Zien", que representan este intercambio entre ambas posturas ${ }^{7}$.

La unión de las reivindicaciones de género con otras reivindicaciones de grupos en desventaja o de minorías invisibilizadas es relativamente frecuente, ya que convergen en determinados objetivos. No obstante conviene no perder de vista que esta estrategia conlleva en ocasiones el debilitamiento del sujeto colectivo mujeres que debe tenerse en cuenta en cada una de las otras diferencias. Desde el punto de vista de la toma de decisiones políticas los legisladores no interesados en la igualdad de género pueden utilizar, la unificación de la problemática de la igualdad de género con otras problemáticas de minoría o grupos en desventaja para priorizar las demandas de estos posponiendo o las de equidad de género. La atención a otras desigualdades nunca debería ser un mecanismo justificador para desatender las demandas de igualdad de género. Por poner un ejemplo, en la LAAD algunos actores sociales, como los mayores y las personas con diversidad funcional, han sido consultadas en mayor medida, que otros colectivos, como las organizaciones de mujeres, y sus propuestas se han tenido más en cuenta, aunque tampoco su representación es muy decisoria en la toma de decisiones.

Estas voces contribuyen a replantear los términos del debate, a cuestionar la centralidad del mercado y constituyen un ejemplo de apuestas por poner en el centro la "buena vida" de las personas. Aún así, podemos hablar de que el resultado de la LAAD y los marcos normativos que difunde, que tienen consecuencias prácticas, dependen de la lucha simbólica de diversos actores sociales por hacer representar sus intereses. Y entre estos actores sociales, los movimientos feministas no son los únicos ni siquiera los más importantes. Podemos señalar que además existen voces

${ }^{7}$ El resultado de los debates que tienen se publica en el libro publicado en 2011 por Traficantes de Sueños: "Cojos y precarias haciendo vidas que importan. Cuaderno sobre una alianza imprescindible". 
conservadoras $^{8}$ y recientes posturas mal llamadas feministas (Hoff, 1994), que vuelven a reconstruir los viejos estereotipos de género y sostienen de nuevo la naturalización de las diferencias. No podemos dejar de hacer referencia al nuevo neurosexismo (Brinzendine, 2010) representado por textos de amplia difusión y títulos muy comerciales como "el cerebro femenino" o "el cerebro masculino" que con un lenguaje muy accesible, pretendidamente científico y sobre todo, muy afín a los viejos clichés y tópicos de la feminidad y la masculinidad, aunque adornados con un ligero toque de valor simbólico, acentúa las diferencias de género, las naturaliza y ofrece una fácil conclusión que consiste en el mejor aprovechamiento de las viejas características femeninas si se destinan al ámbito del hogar. El hecho de las pretensiones ideológicas de dichos textos hayan sido detectadas y denunciadas por otros autores (Fine, 2011) no significa que hayan sido desprovistos de influencia social.

Los actores sociales están en constante pugna por dar sentido a una manera $u$ otra de observar la realidad. De este modo, observamos en la LAAD voces más visibles y otras más invisibles. Los mecanismos puestos en marcha para la elaboración de esta política pública, denotan la prevalencia de unos actores y de sus propuestas por encima de otros. El Libro Blanco, en el que participan expertos del mundo científico y político; el diálogo social, en el que toman decisiones el gobierno, junto con los sindicatos y la patronal; o el debate parlamentario, en el que se representan los intereses de los distintos partidos políticos y Comunidades Autónomas, son mecanismos eficaces de intervención en la política institucional. Los grupos sociales ausentes en este tipo de mecanismos, tienen más dificultades para llevar a cabo sus propuestas.

Los debates en torno al modo de financiación del sistema (vía seguridad social o vía impuestos), que han enarbolado las Comunidades Autónomas, o la compatibilidad de prestaciones económicas, copago y la asunción de titularidad mixta de los servicios (privada, pública y concertada); son muestras de la presencia de diferentes intereses representados en el diseño de la política.

El establecimiento de ciertos marcos normativos por encima de otros es resultado de las múltiples pugnas por el sentido de los distintos actores sociales, así como de la historia social de cada estado entorno a los presupuestos de género. Existen mecanismos de poder, que establecen ciertos discursos como "verdaderos", como por ejemplo el establecimiento de voces autorizadas a través de mecanismos de participación política, y el ocultamiento y la falta de representación de otras voces que aparecen como desautorizadas o invisibles. Por ello, es importante la presencia

${ }^{8}$ El presidente del PP de Andalucía ha declarado que apoyará todas las políticas relativas a la mujer que se pongan en marcha desde el Gobierno central y que persiguen "recuperar los valores familiares que, desde que la mujer trabaja, se han perdido". "Cuando esas feministas vuelvan a estar cómodamente en su casa, educando a sus hijos y cuidando de sus familias, nos lo agradecerán" (Javier Arenas). 
de actores sociales, como las organizaciones de mujeres y otros, que contribuyen al cuestionamiento de los aprioris en relación a la organización social en torno a los cuidados, plantean una reformulación de los tiempos de trabajo y vida, la dignificación del trabajo de los cuidados, o la reorganización social que promueva una "buena vida" y la importancia de descentrar los mercados y poner en el centro las necesidades de las personas, de priorizar la vida por encima de las necesidades del capital.

La persistencia de los estereotipos de género, así como la importancia de nuevas interpretaciones naturalistas de las diferencia nos lleva a concluir que la sociedad sigue esperando mayoritariamente que sigan siendo las mujeres las que realicen las conductas prosociales, las que atiendan a los otros, las que nutran, las que sean mas amistosas, generosas e interesadas en los demás. A pesar de todos los cambios en la participación social de las mujeres y en la implicación en las diversas condiciones de la vida laboral, éstas siguen mostrando mas actividades dirigidas a lo interpersonal, lo relacional y comunal mientras que los varones prefieren las actividades dirigidas a la mejora del estatus y a colectivos específicos (Eagly, 2009). Lo cual es un ejemplo de la persistencia de la socialización de género. En el mismo sentido debemos interpretar la feminización del voluntariado, el Anuario de la Fundación Luis Vives estima que el 63\% de los voluntarios son mujeres (Edis, 2010).

A la resistencia al cambio que se puede esperar de la persistencia de estas actividades, hay que sumar las expectativas que mantienen los jóvenes y los niños de diferentes contextos, acerca de sus roles futuros. Incluso en países de amplia trayectoria democrática y de avances en la igualdad, niños (Fulcher, 2011) y jóvenes de diferentes) niveles sociales y educativos (Ferriman et al., 2011) difieren claramente en la importancia que concedes a su futura dedicación a las tareas profesionales y a las tareas del cuidado. Los papeles tradicionales de Hombre proveedor del hogar y mujer soporte afectivo de la familia están muy activos y presentes en las identificaciones d genero actuales. Si bien las mujeres insisten en la búsqueda prioritaria de la autonomía social y económica a través del trabajo, vuelven a caer en una relación neotradicional en la cual son ellas mucho mas que los varones las que posponen el aplazamiento del matrimonio o rediseñan la maternidad, pero el varón sigue teniendo el rol principal de proveedor (Gerson, 2009). La posibilidad de una sociedad no marcada por el genero, con unas responsabilidades morales que descansen en la simple categoría de "persona" sigue siendo vista como una utopía (Risman, Lorber y Sherwood, 2012).

Por ello, al considerar como una prioridad la consecución de una buena vida y la necesidad de poner en el centro la vulnerabilidad de las personas, nunca se puede desatender la justicia retributiva y el reparto de responsabilidades entre los hombres y las mujeres, es decir, de nuevo, la corresponsabilidad en todas y cada una de las tareas que dicho valor implica. 


\section{Conclusiones}

Los trabajos de cuidados han sostenido y sostienen aun hoy el entramado de la vida social a costa de una desigualdad e injusticia de género, ya que se ha depositado sobre las mujeres su coste económico y psicológico. Sin embargo su importancia se ha minimizado y el correspondiente esfuerzo y coste ha sido desvalorizado y desconocido para la economía y la sociedad. La necesidad de cuidados no es algo que afecta solo a algunas personas mientras otras están a salvo. La dependencia o mejor dicho, la interdependencia no es ningún síndrome de patología médica, sino un estado natural e inevitable en los seres humanos en todas las etapas de nuestra vida, sobretodo en el nacimiento y en la vejez. Como tal debe ser reconocida, cada vez mejor visibilizada y atendida como necesidad básica que es. Por tanto, los cuidados deben situarse en el centro de la organización social. Sus costes económicos y emocionales deben ser evaluados con precisión y distribuidos con justicia de género. La redistribución de las tareas del cuidado entre hombres y mujeres es un componente básico de la equidad de género.

La ley de dependencia no contiene un potencial transformador de la redistribución de los cuidados entre los hombres y las mujeres. No contiene una percepción realista de los mecanismos que afectan a la distribución del poder en el ámbito del hogar ni de la consiguiente desigualdad en la asignación de las tareas en la sociedad entre familia (mujeres), mercado, y sociedad civil, y en la posible inercia de la situación en el futuro. Tampoco reconoce ni promueve mecanismos para remover y eliminar las resistencias al cambio por parte de los hombres y de las mujeres.

Las transformaciones en la implicación de los hombres en los cuidados dependerán pues de dos cuestiones: los factores estructurales y los de socialización. Los estructurales se derivan de la transformación del mercado de trabajo para las mujeres, de la disminución del tamaño de las familias y de las oportunidades de las mujeres en la promoción laboral.

Los factores estructurales parecen apuntar más a la estabilidad que al cambio. Las mujeres mayores seguirán cuidando más que los varones, puesto que su esperanza de vida es mayor. Pero al mismo tiempo, serán también las más atendidas, ya que su esperanza de edad más avanzada hace esperar, como ya ocurre hoy día, más deterioros en ellas. Siguiendo las tendencias evolutivas de la sociedades occidentales en las que las mujeres tienen más esperanza de vida y menos posibilidades de trabajo que los hombres, en el futuro estarán más necesitadas de ayuda y, al mismo tiempo, más disponibles para aceptar una tarea mal pagada que además está tan relacionada con los roles de género tradicionales. El modelo de cuidados familiar, el más frecuente en nuestra sociedad, sigue implicando gran dependencia entre la persona cuidada y el cuidador/a y, una responsabilización casi total del cuidador/a y un tiempo de dedicación muy elevado, en el que se realiza un esfuerzo intenso. Este modelo se puede denominar modelo materno, contrapuesto al modelo de profesionalización de los cuidados. La profesionalización , que daría entrada mas fácilmente a los varones, sigue siendo un tema de debate que no se resolverá fácilmente, no 
solo por los costes y dificultades que conlleva sino porque persisten las resistencias a la transformación de las identidades de los hombres y las mujeres.

Las tendencias actuales hacia la creciente incorporación de los varones en algunas dimensiones de cuidado, no deben producir el descuido en el progreso de dicha incorporación ni provocar la ingenua confianza de que seguirá en aumento consecuente al desarrollo económico y a la cada vez mayor incorporación de las mujeres al mercado de trabajo. No podemos tomar un simple señuelo de igualdad como un índice de transformación que será estable y duradero. Por otra parte, la consecución de la igualdad entre cualquier grupo social, no solo la de género, dista mucho de ser un proceso continuo y lineal sino que está sujeto a procesos de retroceso, conflicto y recomposición según las condiciones económicas y los cambios en el poder de los grupos implicados.

El efecto de las presiones socializadoras es incierto. Si bien parece existir cierta erosión de los estereotipos y una mayor afinidad de los varones hacia el cuidado, se plantean y cobran nueva fuerza las naturalizaciones diferencialistas, desde posturas conservadoras, el llamado feminismo darwinista ,la crítica destructora de la teoría del origen social de las diferencias de género, y el neurosexismo, que por caminos diversos confluyen en la reedición de las misma perspectivas diferencialistas y discriminatorias tradicionales y que pueden trasladarse al futuro hacia una reformulación de la división del trabajo.

Las deconstrucción de las categorías de género han sido muy útiles y fecundas para hacer surgir en las mujeres nuevas y más variadas identificaciones y han abierto el camino a múltiples modos de ser mujer y a la deconstrucción del género. Sin embargo esa deconstrucción no ha tenido lugar del mismo modo en las identificaciones de los varones que siguen manteniendo fuertes resistencias a incorporar aquellas dimensiones que se conectan mas fuertemente a lo "femenino" Sería necesario profundizar en las nuevas opciones que se han abierto tímidamente y analizar con mas detalle la problemática psicosocial que impide su progreso Pero lo mas amenazante para la transformación de las identidades de genero y los papeles en las tareas del cuidado son las identificaciones naturalizadoras que vuelven a dar por supuesto que la mujer está mas capacitada por naturaleza y tiene mas recursos para desempeñar las tareas de nurturance y afectividad, que se vienen sucediendo por parte de posturas conservadoras a colación del periodo de crisis económica y de los cuidados. De esta naturalización se deriva espontáneamente la responsabilización moral y la delegación de las tareas a las mujeres, que opera con toda facilidad en los discursos sociales de la actualidad, de modo que se pretende una vuelta a la división sexual del trabajo y se asigna a las mujeres la responsabilidad y el papel de sostener la vulnerabilidad que se acrecienta en la época actual de crisis de la vida.

Si bien la deconstrucción de la feminidad ha recorrido un importante camino, la deconstrucción de la masculinidad es apenas incipiente. No obstante, la redefinición de sus identificaciones es un proceso complementario e igualmente necesario. La reorganización de sus deseos y expectativas como género debería incluir el objeto que hemos señalado como sustantivo en la posible transformación social del cuidado: poner el sostenimiento de la vida humana en el centro de los valores sociales e 
investir de valor el cuidado de otros y de si mismos. Ese movimiento sería verdaderamente transformador de las identidades y de los roles de genero en el futuro.

Volvemos de este modo a situar en primer plano una de las demandas más genuinas y patentes del feminismo, la búsqueda de la equidad de genero. Y cualquier ley que atienda a las necesidades de dependencia debe situar la perspectiva de género en el principio de sus objetivos en la explicitación de cada una de sus propuestas y normativas. Precisamente porque es en este territorio del cuidado donde mas fácilmente se deslizan los viejos tópicos y donde están mas fuertemente arraigados los viejos intereses, mantenidos no sólo por los poderes públicos o por los varones, sino por las mujeres que han interiorizado en el proceso de socialización, desde épocas evolutivas muy tempranas, las exigencias del cuidado.

\section{Bibliografía}

Apfelbaum, E. (1999). Relations of Domination and Movements for Liberation: An Analysis of Power between Groups. Feminism \& Psychology. Vol. 9 Núm. 3, 267-272.

Ashforth ,B.E. y Humphrey, R.H.(1993). Emotional labour in service roles. Academy of Management Review, Vol. 3 Núm. 1, 88-115.

Bettio, F., Simonazzi, A. y Villa, P. (2006). Change in care regimes and female migration: the "care drain" in the Mediterranean». Journal of European Social Policy. Vol. 16 Núm. 3, 271-285.

Brinzendine, L. (2010). El cerebro femenino. Barcelona: RBA Libros

Calasanti, T., Slevin, K. F. y King, N. (2006). Ageism and Feminism: From Et Cetera to Center. NWSA Journal. Vol. 18 Núm. 1, 13-30.

Castejón P, Esparza C y Abellán A. (2007). Salud, dependencia y cuidados. En IMSERSO (Ed.), A propósito de las condiciones de vida de las personas mayores (pp. 65-82). Madrid: IMSERSO.

Centro de Investigaciones Sociológicas. (1998). Encuesta sobre la soledad en las personas mayores. Madrid: CIS.

Cohen, C. Colantino, A. y Vernich, L. (2002). Positive aspects of caregiving: rounding out the caregiver experience. International Journal of Geriatry. Vol. 17, 184-188.

Covas, S. (2009). Hombres con valores igualitarios: historias de vida, logros alcanzados y cambios pendientes. Madrid: Ministerio de Igualdad. 
Crespo. M. y López, J. (2008). Cuidadoras y cuidadores: el efecto del género en el cuidado no profesional de los mayores. Boletín sobre el Envejecimiento: Perfiles y tendencias. Núm. 35 .

Durán, M. A. y García, S. (2005). Presente y Futuro del Cuidado de Dependientes en España y Alemania, IMSERSO. Boletín sobre el Envejecimiento: Perfiles y Tendencias, Núm.16.

Durán, M. A. (1999). Los costes invisibles de la enfermedad. Madrid: Fundación BBVA.

Eagly, A.H. (2009). The his o hers of prosocial behavior: An examination of the social psychology of gender. American Psychologyst. Vol. 64 Núm. 8, 644-658.

Edis. (2010). Anuario del Tercer Sector de Acción Social en España. Madrid: Fundación Luis Vives.

Ferriman, K., Lubinski, D., Benbow, C. P. (2009). Work preferences, life values, and personal views of top math/science graduate students and the profoundly gifted: Developmental changes and gender differences during emerging adulthood and parenthood. Journal of Personality and Social Psychology. Vol. 97 Núm.3, 517-532.

Fine, C. (2011). Cuestión de sexos. Barcelona: Roca Editorial.

Fine, M. y Glendinning, C. (2005). Dependence, independence or inter-dependence? Revisiting the concepts of 'care' and 'dependency'. Ageing and Society. Vol. 25, 601-621.

Fulcher, M. y Coyle, E. F. (2011). Breadwinner and caregiver: A cross-sectional analysis of children's and emerging adults' visions of their future family roles. British Journal of Developmental Psychology. Vol. 29, 330-346.

Fundación Edad y Vida (2004). Estudio del modelo de atención a las personas mayores con dependencia en España. Barcelona: Fundació Institut Català de l'Envelliment. Universitat Autònoma de Barcelona.

Gerson, K. (1994). No man's land: Men's changing commitment to work and family. Nueva York: Basic Book.

Gerson, K. (2009). The Unfinished Revolution: How a New Generation Is Reshaping Family, Work, and Gender in America. New York: Oxford University Press 
Herrera, E., Martín, V., Bello, E., Muñoz, I. y Sitges, J. (2011). Cuidadores profesionales en España: formación, empleabilidad y oportunidades de empleo. Actas de la dependencia, Vol. 1. Revisado el 15 de Mayo en http://www.fundacioncaser.es/sites/default/files/20110301_004_0.pdf.

Hoff, C. (1994). Who Stole Feminism? How Women Have Betrayed Women. Simon and Schuster. Vol. 22.

IMSERSO (2004). Libro blanco de la dependencia. Madrid: IMSERSO.

IMSERSO (2005a). Cuidados a las personas mayores en los hogares españoles. El entorno familiar. Madrid: IMSERSO.

IMSERSO (2005b). Cuidado a la dependencia e Inmigración. Informe de resultados. Madrid: Ministerio de Trabajo y Asuntos Sociales.

Herce, J. A., Labeaga,J. M., Sosvilla, S. y Ortega, C. (2006). Sistema Nacional de Dependencia. Evaluación de sus efectos sobre el empleo. Colección de estudios Serie Dependencia. Madrid: IMSERSO.

Kramer, B. J. (2002). Men caregivers: an overview. En B. J. Kramer y E. H. Thompson (Eds.), Men as caregivers (pp. 3-19). Nueva York: Springer

Larrañaga, I., Martín, U., Bacigalupe, A., Begiristáin, J. M., Valderrama, M. J., Arregi, B. (2008). Impacto del cuidado informal en la salud y la calidad de vida de las personas cuidadoras: análisis de las desigualdades de género. Gaceta Sanitaria, Vol. 22 Núm. 5, $443-450$.

Letablier, M. T. (2007 El trabajo de cuidados y su conceptualización en Europa. En C. Prieto (Ed.) Trabajo, genero y tiempo social (64-85). Madrid: Hacer.

Lewis, J. y Daly, M. (2011). El concepto de social care y los Estados de bienestar contemporáneos. En C. Carrasco, C. Borderías y T. Torns (Eds.). El trabajo de cuidados: Historia, teoría y políticas (225-252

Lynch, K. (2007). Love Labour as a Distinct and Non-Commodifiable Form of Care Labour. Sociological Review. Vol. 55, Núm. 3, 550-70.

Merla, L. (2006). No trabajo y me siento bien: Cambios en la división sexual del trabajo y dinámicas identitarias de padres en casa en Bélgica. Cuadernos de Relaciones Laborales. Vol. 24, 111-127.

Morris, J., y Feldman, D. (1996). The dimensions, antecedents, and consequences of emotional labor. Academy of Management Review. Vol. 21, 986-1010. 
Nolan, M, Grant, G, Keady, J. (1996). Understanding family care: a multidimensional model of caring and coping. Buckingham: Open University Press.

Observatorio Navarro de Empleo (2009). Servicios domésticos y servicios personales en el hogar. Revisado el 10 de Abril d 2012 en http://www.ccoonavarra.org/files/Publicaciones/PUBLICACIONES_GABINET E/2010/informecompleto_servicos_domesticos_y_personales.pdf

Pérez Orozco, A. y López Gil, S. (2011). Desigualdades a flor de piel: Cadenas globales de cuidados. Concreciones en el empleo del hogar y políticas públicas. Santo domingo ONU Mujeres.

Pinquart, M. y Sörensen, S. (2006). Gender differences in caregiver stressors, social resources, and heath: an update meta-analysis. Journal of Gerontology. Vol. 61B, 33-45.

Pérez, L. (2006). La estructura social de la vejez en España. Nuevas y viejas formas de envejecer. Madrid: IMSERSO.

Puga, M.D. (2007). Redes sociales y salud en W.AA . A propósito de las condiciones de vida de las personas mayores. Madrid: IMSERSO.

Razavi, S. (2007). The political and social economy of care in a developmentcontext. Conceptual issues, research questions and policy options, Gender and Development, Programme Paper Number 3. Genova Suiza: UNRISD

Ribero, O. (2005). Quando o cuidador e um homem. En C. Paúl y A.M. Fonseca (Eds.), Envelhecer em Portugal (pp. 231-254). Lisboa: Climepsi.

Ridgeway, C.L. y Smith-Lovin, L. (1999). The gender system and interaction. Annual Review of Sociology. Vol. 25, 191-216.

Risman, B. (1998). Gender vertigo. New Haven, CT: Yale University Press.

Rivera, J. (2001). Redes familiares en el cuidado del anciano con demencia. Análisis evolutivo de un estudio poblacional. Madrid: Consejo Económico y Social. Comunidad de Madrid.

Rodrigues, R.A.P., Andrade, O.G., Marqués, S. (2001). Representaciones sociales del cuidado del anciano en trabajadores de salud en un ancianato. Rev.latinoam.enfermagem, Ribeirão Preto. Vol. 9 Núm. 1, 7-12.

SAAD-IMSERSO (2012). Estadísticas del sistema para la autonomía y la Atención a la dependencia. Revisado el 31 de Mayo en http://www.imsersodependencia.csic.es/ documentos/estadisticas/indicadores/saad/2012-05/estadisticas-saad-may-2012.pdf 
Saltman, J. (1992). Una teoría integrada de la estabilidad y el cambio. Madrid: Cátedra.

Serrano, A. y Artiaga, A. (2012) Desorden semántico y crisis de los cuidados: El ejemplo de la $L A A D$. Trabajo no publicado, presentado en el Seminario de investigación del Departamento de Psicología Social.

Simonazzi, A. (2009). Care regimes and national employment models. Cambridge Journal of Economics. Vol. 33, Núm. 2, 211-232.

Taylor, S., (1998). Emotional Labour and the New Workplace. En P. Thompson y C. Warhurst (Eds.), Workplaces of the Future pp. 84-103. Basingstoke : Macmillan

Thompson, E. y Kramer, B. (2005). Men as caregivers. New York: Prometheus Books.

Tobío, C., Agulló Tomás, M. S. ,Gómez M. V. y Martín Palomo, M. T. (2010). El cuidado de las personas. Un reto para el siglo XXI. Barcelona: Fundación "la Caixa". 